\title{
Mobile Source Emission Control Cost-Effectiveness: Issues, Uncertainties, and Results
}

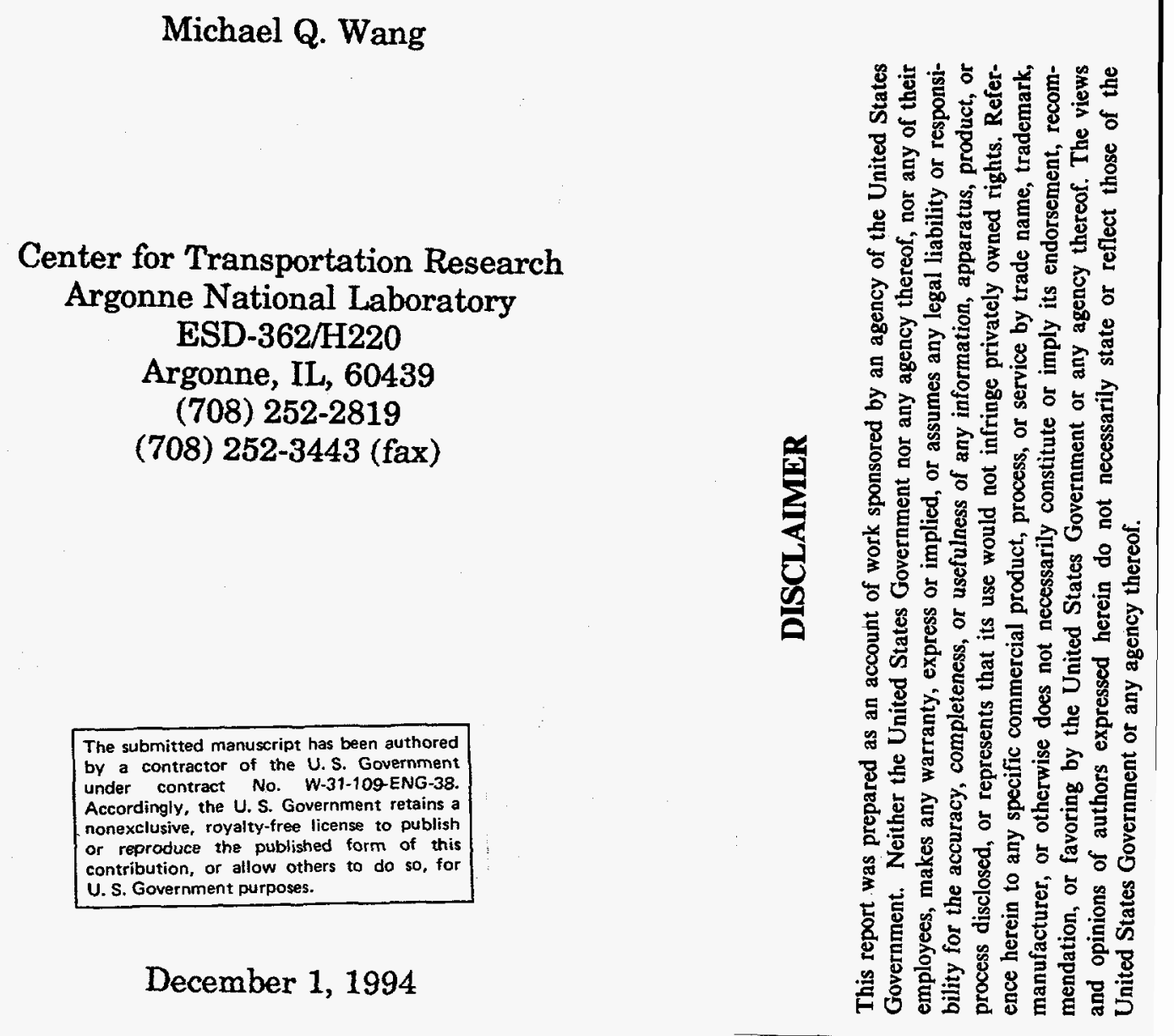

Paper to be Presented at the Reformulated Fuels Conference Houston, Texas January 31 - February 2, 1995 


\section{DISCLAIMER}

Portions of this document may be illegible in electronic image products. Images are produced from the best available original document. 


\title{
Mobile Source Emission Control Cost-Effectiveness: Issues, Uncertainties, and Results
}

\author{
Michael Q. Wang \\ Staff Researcher, Center for Transportation Research \\ Argonne National Laboratory
}

\section{Introduction}

Emissions from mobile sources undoubtedly contribute to U.S. urban air pollution problems. Consequently, mobile source control measures, ranging from vehicle emission standards to reducing vehicle travel, have been adopted or proposed to help attain air quality standards. To rank various mobile source control measures, various government agencies and private organizations calculate cost-effectiveness in dollars per ton of emissions reduced. Arguments for or against certain control measures are often made on the basis of the calculated cost-effectiveness. Yet, different studies may yield significantly different costeffectiveness results, because of the various methodologies used and assumptions regarding the values of costs and emission reductions. Because of the methodological differences, the cost-effectiveness results may not be comparable between studies. Use of incomparable costeffectiveness results may result in adoption of ineffective control measures.

This paper first discusses some important methodological issues involved in costeffectiveness calculation for mobile sources and proposes appropriate, systematic methods for dealing with these issues. Various studies have been completed recently to evaluate the costeffectiveness of mobile source emission control measures. These studies resulted in wide variations in the cost-effectiveness for same control measures. Methodological assumptions used in each study are presented and, based on the proposed methods for cost-effectiveness calculation, adjustments are applied to the original estimates in each study to correct inappropriate methodological assumptions and to make the studies comparable. Finally, mobile source control measures are ranked on the basis of the adjusted cost-effectiveness estimates.

\section{Methodological Issues in Cost-Effectiveness Calculation}

Calculation of cost-effectiveness appears simple and straightforward - total cost is divided by total emissions reduced. However, studies vary in terms of the values of costs and emission reductions used, the cost items considered, and the method for calculating emission reductions. Although the first may be a technical issue, the latter two are methodological. It is these methodological arguments (on which the various studies are based) that create study results that cannot be compared. In order to make the studies comparable, these methodological arguments must be settled. The issues discussed below are related to methodological, rather than technical arguments.

\section{Cost-Related Issues}

Private Costs vs. Social Costs. No doubt private costs should be included in costeffectiveness calculation. In fact, all past studies have accounted for private costs. On the other hand, social costs - the costs not paid by individuals, but by society to the extent possible, directly or indirectly - are often ignored. Social as well as private costs should be included in cost-effectiveness calculation. For example, use of alternative fuels helps decrease the nation's dependence on foreign oil and reduce emissions. It may be appropriate, then, to subtract the monetary benefit of reducing our dependence on foreign oil from the costs of alternative fuels. Another example involves using transportation control measures (TCMs) 
to reduce emissions. TCMs are designed to reduce emissions by decreasing vehicle miles traveled (VMT), which also reduces the demand for further expansion of the transportation infrastructure. Costs avoided in infrastructure expansion due to VMT reduction may need to be subtracted from the costs of TCMs.

In calculating social costs, costs transferred from one group to another group should not be included, because they are simply not net costs to society. The obvious example of these transfer costs are vehicle registration fees and motor fuel taxes.

Costs at the Manufacturer vs. the Consumer Level. It is often not clear whether costs specified in a study are at the manufacturer or the consumer level. Worse, the same study may use manufacturer costs for some cost items and consumer costs for others. For example, some studies on alternative-fuel vehicle (AFV) cost-effectiveness use vehicle incremental costs at the manufacturer level but incremental fuel costs at the consumer level. This inconsistency must be avoided in cost-effectiveness calculation. Because the costs and profit margins from manufacturers to consumers represent real costs, costs at the consumer, not the manufacturer, level should be used in calculating cost-effectiveness.

\section{Emission-Related Issues}

Baseline Emissions. Emission reduction by a control measure is usually calculated by applying an emission reduction rate to the baseline emission. Thus, the higher the baseline emission, the higher the emission reduction that results from the measure. Obviously, the control measures used in baseline emissions calculation are critical in determining the magnitude of baseline emissions. Yet, it is often uncertain what measures should be considered baseline control measures. For example, in estimating the cost-effectiveness of reformulated gasoline (RFG), current vehicles, Tier 1 vehicles, or Tier 2 vehicles may be used in baseline emission calculations. In estimating the cost-effectiveness of vehicle emission standards, conventional gasoline or RFG may be considered. We propose that, in evaluating a given control measure, all the control measures that have already been adopted be considered for baseline emission calculation.

Some control measures may be integrated to reduce emissions. An example is California's low-emission vehicle (LEV) standards which consider both vehicle and fuel requirements. It is proper to evaluate the integrated measures as a complete program, and not to separate them. If for the purpose of evaluating incremental policies, it becomes necessary to separate some measures from others, the measures in interest can be evaluated with or without other measures as baseline control measures, depending on which will be implemented first. If the other measures is included as baseline control measures, both costs and emission reductions of the measures in interest need to be estimated by considering the other measures. Often, the emission reduction of a given measure is estimated with some control measures being considered baseline control measures, and the cost of the measure is estimated without considering these same control measures. This mistake must be avoided in cost-effectiveness estimation.

Annual vs. Seasonal Emissions. Calculation of cost-effectiveness has been based primarily on annual emission reductions. Recently, some researchers have argued that, because the purpose of emission reductions is to meet air quality standards, emissions during the nonattainment season (e.g., summer for ozone precursor emissions and winter for carbon monoxide [CO] emissions) should be used in calculating cost-effectiveness. Accordingly, some recent studies have been based on seasonal emissions. Use of seasonal emissions is especially important when comparing the measures to reduce emissions in the nonattainment season with the measures to reduce emissions year-round. For example, while RFG requirements 
are enforced in summer to reduce hydrocarbon $(\mathrm{HC})$ and nitrogen oxides $\left(\mathrm{NO}_{\mathrm{x}}\right)$ emissions for ozone attainment, vehicle emission standards reduce $\mathrm{HC}$ and $\mathrm{NO}_{\mathrm{x}}$ emissions year-round. Cost-effectiveness based on annual emission reductions with vehicle standards tends to give credit to vehicle standards for the emission reductions in attainment seasons, which have little or no value for ozone attainment.

Those who prefer to use seasonal emissions explicitly or implicitly believe that emissions in attainment seasons have no value. This belief is based on the perception that there are air pollution thresholds below which no air pollution damages occur and at which air quality standards are set. However, studies of air pollution risk assessment have revealed that such thresholds may not exist. Emissions cause damages, though less severe, even at lower concentrations. Thus, emissions in attainment seasons cannot be ignored completely, though they may be assigned less value. Emissions in attainment seasons may be discounted on the basis of their damage values, and then added to the emissions in nonattainment seasons.

Use of seasonal emissions in calculating cost-effectiveness undoubtedly causes high control costs. Comparison between seasonal emission-based cost-effectiveness and annual emission-based cost-effectiveness, as done in some studies, may result in misleading conclusions.

Emissions in Nonattainment us. Emissions in Attainment Areas. Similar to the argument for using seasonal emissions, some researchers maintain that only emission reductions in nonattainment areas should be used in cost-effectiveness calculation. Use of emission reductions in nonattainment areas is especially important in comparing mobile source control measures because some measures (such as vehicle emission standards) may inevitably be applied to both nonattainment and attainment areas, but other measures (such as RFG requirements and the inspection and maintenance [I/M] programs) can be applied only to nonattainment areas. However, as stated above, completely ignoring emissions in attainment areas is questionable. Emissions in attainment areas should be discounted based on emission damages in the area, and then added to the emissions in nonattainment areas. Multiple-Pollutant Emission Reductions. Most mobile source control measures reduce emissions for more than one pollutant. In order to calculate the control cost for a multiplepollutant control measure, emission reductions of all the pollutants must be combined, or a cost must be allocated to each pollutant affected. Most past studies combined emissions using either of the following methods. For the first method, emissions of $\mathrm{HC}, \mathrm{CO}$, and $\mathrm{NO}_{\mathrm{x}}$ are added together as $\mathrm{HC}+\mathrm{CO} / 7+\mathrm{NO}_{x}$, and emissions of particulate matter (PM), sulfur oxide $\left(\mathrm{SO}_{\mathrm{x}}\right)$, and air toxics are usually ignored. CO emissions are divided by a factor of seven based on the belief that $\mathrm{HC}$ or $\mathrm{NO}_{x}$ damage is seven times as great as $\mathrm{CO}$ damage. For the second method, emissions of various pollutants are added together using the damage value of each pollutant as the weighing factor. The first method is rough, but simple. The second method is theoretically correct, and should be used to the extent possible.

To allocate the control cost to the various pollutants affected, engineering analysis of the effort spent to control each pollutant can theoretically be conducted. However, in reality, it is generally impossible to allocate portions of the aggregate effort to individual pollutants. An alternative method is to select a primary pollutant for evaluation and calculate the cost for that pollutant by subtracting the monetary benefits of emission reductions for other pollutants from the total cost. Lareau (1994) used this method to calculate volatile organic compound (VOC) control costs for different control measures. He estimated the monetary benefits of emission reductions for $\mathrm{CO}$ and $\mathrm{NO}_{\mathrm{x}}$ on the basis of $\mathrm{CO}$ attainment status and the 
importance of $\mathrm{NO}_{\mathrm{x}}$ in ozone formation. He implicitly assumed zero monetary value for $\mathrm{CO}$ in $\mathrm{CO}$ attainment areas and zero value for $\mathrm{NO}_{\mathrm{x}}$ in the areas where $\mathrm{NO}_{x}$ was unimportant in ozone formation.

Sometimes, the same study may use both the emission combination and the cost allocation method. For example, in estimating the cost-effectiveness of California's Phase 2 RFG requirements, the California Air Resources Board (CARB 1991) first allocated 20\%-50\% of the RFG cost to air toxic reductions, and then divided the remaining cost by the sum of $\mathrm{HC}+\mathrm{CO} / 7+\mathrm{NO}_{\mathrm{x}}+\mathrm{SO}_{\mathrm{x}}$.

One way or another, emission reductions of all pollutants should be taken into account in calculating cost-effectiveness. Ignoring emission reductions for some pollutants results in upward-biased cost-effectiveness results.

Estimated vs. Actual On-road Emissions. Virtually all past studies relied on EPA's Mobile or CARB's EMFAC model to estimate emission reductions. Despite continuous efforts to upgrade and refine Mobile and EMFAC, the current versions (Mobile5a and EMFAC7F) are still believed to substantially underestimate actual on-road emissions. HC and CO emissions are believed to be underestimated by as much as $200 \%$. Underestimation of onroad emissions by the models is caused primarily by off-cycle emissions; activity factors such as cold starts, hot soaks, and multiple-day diurnals; and super-emitting vehicles. Emission reductions based on Mobile5a or EMFAC7F may well under-represent actual reductions, causing higher calculated control costs. To reflect actual on-road emission reductions in a cost-effectiveness study, researchers should establish a case with adjusted on-road emissions and calculate cost-effectiveness for the case. On-road emission adjustments are especially important when comparing mobile source cost-effectiveness and stationary source costeffectiveness, because the discrepancy between estimated emissions and actual emissions for stationary sources is usually much less than for mobile sources.

Emission Discounting. The present value of life-cycle costs of vehicles is usually calculated by discounting the future costs to the present cost. Discounting cost items reflects the fact that dollars in the future are worth less than present dollars because of the lack of investment opportunity for future dollars and because of price inflation. If real-term dollars are used in cost estimates, the effect of price inflation is eliminated; the discount rate adopted should be a real-term discount rate to reflect the lack of investment opportunity for future dollars. If current-term dollars are used in cost estimates, the discount rate adopted should be a current-term discount rate to reflect both inflation and the lack of investment opportunity. The current-term discount rate (usually around 10\%) should be higher than the real-term discount rate (around 5\%).

While costs are indisputably discounted, vehicle life-cycle emissions are often the straight sum of annual emissions without discounting. Some argue that because emissions are in the physical term, rather than in the monetary term, they should never be discounted. However, while the cost of a measure is represented by dollars spent, its benefit is represented by emission reductions. To put the measure into the cost-benefit context through cost-effectiveness analysis, both costs and emissions should be discounted. Because there is no such inflation effect on physical units such as emissions, a real-term discount rate should always be used for emission discounting, regardless of which rate - real-term or currentterm - is used for cost discounting.

Some have argued that a negative, rather than a positive, rate should be used for emission discounting. Use of a negative discount rate means that future emissions are worth more than current emissions. The rationale is that, while the current generation has some 
control of emissions for future generations, future generations have no control over the current generation's actions. Assigning a higher value to future emissions helps limit the consequence of the current generation's actions on future generations. Thus, use of a negative discount rate is seemingly intended to address the issue of equity among generations. However, mobile source emission discounting is usually applicable for the lifetime of a motor vehicle, which is about 15 years. Inter-generational inequity rarely exists over a 15-year period.

The cost-effectiveness of some mobile source control measures is calculated on the basis of annual, rather than lifetime, emission reductions. Such measures include the I/M program and RFG requirements. The costs of these measures are usually annualized. Annualized costs and annual emissions are used to calculate cost-effectiveness. Emission discounting is not applicable to these measures.

Program Cost-Effectiveness vs. Component Cost-Effectiveness. The cost-effectiveness of one component of a control program can be calculated on the basis of its incremental cost and incremental emission reductions. Meanwhile, the cost-effectiveness can be estimated separately for the entire program. Lareau (1994) maintained that component costeffectiveness should be estimated in order to determine a least-cost program (Lareau referred to the component cost-effectiveness as marginal cost-effectiveness, and the program costeffectiveness as average cost-effectiveness). As an example, he estimated the component costeffectiveness for the transitional low-emission vehicle (TLEV), the LEV, and the ultra lowemission vehicle (ULEV) included in CARB's LEV program. He found that the ULEV is an extremely expensive component of the LEV program.

However, components often interact with one another in terms of costs and emission reductions. It is sometimes unrealistic to separate them and then to estimate marginal costeffectiveness. For example, various components and specifications of gasoline need to be changed collectively in order to meet RFG requirements. It would be inappropriate to separate each component or specification and to estimate its cost-effectiveness, because refiners are very unlikely to change components or specifications separately to meet RFG requirements. In addition, when estimating cost-effectiveness for one component, it is not clear which changes in other components should be included in designing baseline gasoline. At most, RFG component cost-effectiveness only provides some indication of the cost to change some components. It has little value in evaluating RFG requirements in comparison to other control measures.

Review of Past Studies: Major Assumptions and Proposed Adjustments

This section presents a review of past studies on mobile source cost-effectiveness, specifically, the methods used and the methodological assumptions made for each study. Table 1 in the following section present the methods and assumptions in each reviewed study. To allow comparison of these studies, we have proposed certain necessary methodological adjustments for each study. The proposed adjustments generally include consideration of emission reductions of all affected pollutants, use of annual emissions, and application of emission discounting. No adjustments are proposed here for technical assumptions made regarding the values of costs and emission reductions. Original and adjusted costeffectiveness results of each reviewed study are presented in Table 2.

California Air Resources Board 1991

In 1991, CARB estimated the cost-effectiveness of its Phase 2 RFG requirements. CARB estimated baseline emissions from its ozone planning inventory emissions, which in turn relied on EMFAC7EP. Consequently, annual emissions in nonattainment areas were 
considered. CARB took into account exhaust and evaporative emissions of on-road and offroad vehicles, and evaporative emissions of gasoline transportation, storage, and distribution.

In determining total emission reductions by RFG in a target year, CARB assumed no emission reductions for post-1995 model-year vehicles. CARB believed that the phase 2 RFG would be a part of its LEV program after 1995, and assigned all emission reductions to vehicles, but not to RFG. Assigning all emission reductions by the LEV program to vehicles was incorrect, and caused high RFG control cost.

Relying on cost data provided by six refiners in California, CARB estimated that the Phase 2 RFG would cost 12 $\phi-16 \phi$ per gallon more than the Phase 1 RFG. CARB included investment, capital, and operation costs of refineries, but not the cost of RFG's fuel economy penalty (caused by its lower heat content).

In calculating cost-effectiveness, CARB used the sum of $\mathrm{ROG}+\mathrm{CO} / 7+\mathrm{NO}_{\mathrm{x}}+\mathrm{SO}_{\mathrm{x}}$, and allocated $20 \%-50 \%$ of RFG costs to air toxic reductions. PM emission reductions were not included.

CARB's estimates are adjusted in Table 2 by adding a $3 \phi / g a l$. RFG fuel economy penalty. Twenty percent of RFG costs are allocated here to air toxic reductions.

Sierra Research, Inc. 1991

In 1991, Sierra Research, Inc. prepared a study for the Western States Petroleum Association to estimate the cost-effectiveness of California Phase 2 RFG, federal RFG, a leastcost RFG, and ARCO's EC-X RFG. Sierra used CARB's ozone planning inventory emissions to estimate baseline emissions. Thus, annual emissions in nonattainment areas were considered. Unlike CARB, Sierra did not include evaporative emissions of off-road vehicles, but in estimating total RFG emission reductions, Sierra assumed no emission reductions for post-1995 model-year vehicles. Thus, the true emission reductions of the Phase 2 RFG were underestimated substantially.

Sierra adopted RFG costs estimated by some other studies, and included RFG's fuel economy penalty.

In calculating RFG cost-effectiveness, Sierra included emission reductions only for reactive organic gases (ROG) and $\mathrm{NO}_{\mathrm{x}}$, ignored emission reductions for $\mathrm{CO}$ and $\mathrm{SO}_{\mathrm{x}}$ (even though Sierra calculated emission reductions for the latter two pollutants). Sierra did not estimate air toxic emission reductions or consider air toxics in its cost-effectiveness calculation. Sierra calculated component cost-effectiveness for changes in specific fuel parameters.

Sierra's estimates are adjusted in Table 2 to include emissions of $\mathrm{CO}$ and $\mathrm{SO}_{\mathrm{x}}$ as well as ROG and $\mathrm{NO}_{\mathrm{x}}$. Emissions are added together as $\mathrm{ROG}+\mathrm{CO} / 7+\mathrm{NO}_{\mathrm{x}}+\mathrm{SO}_{\mathrm{x}}$. To consider air toxic emission reductions, $20 \%$ of RFG costs are allocated to air toxic reductions.

California Air Resources Board 1993

In 1993, CARB published guidelines for air quality control districts in California to generate and use mobile source emission reduction credits. With the guidelines, CARB provided sample control measures that generate emission reduction credits, and calculated the cost-effectiveness of the sample measures. In particular, CARB calculated costeffectiveness for old car scrappage and for purchase of low-emission transit buses. Each of these is discussed below.

Old Car Scrappage. CARB calculated annual emission reductions of old car scrappage by subtracting the emission rate of the "average fleet" replacement cars from the emission rate of the average retired cars, and then multiplying by the average annual mileage of the retired cars. Thus, annual emissions were considered in calculating cost-effectiveness. Total 
emission reductions by vehicle scrappage were calculated by multiplying annual emission reductions by the remaining lifetime of the scrapped cars. CARB assumed that the remaining life of scrapped cars was 3 years. CARB did not apply emission discounting to total emission reductions. Emission rates of both replacement and scrapped cars were estimated using EMFAC7F. Exhaust emissions of $\mathrm{ROG}$ and $\mathrm{NO}_{\mathrm{x}}$ and evaporative emissions of ROG were taken into account; emissions of other pollutants were ignored.

Use of the EMFAC7F-estimated emission rates for average old cars as the rates for scrapped cars may under-represent the actual emissions of scrapped cars, because these cars are generally poorly maintained, have high mileage, and may have severe emission system deterioration. In fact, emission tests by Unocal on retired cars during Unocal's old car scrappage program showed that scrapped old cars had significantly higher emissions than average old cars.

CARB assumed three offer prices $-\$ 500, \$ 700$, and $\$ 1,000$ and an administrative cost of $\$ 100$ per car to cover the expenses for vehicle scrappage, emission testing, and recordkeeping.

CARB's cost-effectiveness estimates are adjusted in table 2 by including emission reductions of $\mathrm{CO}$ and as well as $\mathrm{HC}$ and $\mathrm{NO}_{\mathrm{x}}$. Specifically, the sum of $\mathrm{HC}+\mathrm{CO} / 7+\mathrm{NO}_{x}$, rather than the sum of $\mathrm{HC}+\mathrm{NO}_{\mathrm{x}}$, is used in calculating cost-effectiveness. We have also discounted emissions with a discount rate of $6 \%$ over the 3-year remaining lifetime.

Low-Emission Buses. CARB considered only $\mathrm{NO}_{\mathrm{x}}$ emission reductions in calculating the cost-effectiveness of low-emission buses. Because emissions of PM, ROG, and CO from current trap-equipped diesel engines are already quite low, CARB believed that emission reductions for these pollutants by low-emission buses would be very limited. However, in reality, buses run on alternative fuels such as methanol and compressed natural gas (CNG) will undoubtedly achieve a significant amount of PM emission reductions.

The emission reduction rate for $\mathrm{NO}_{\mathrm{x}}$ was calculated as the difference between the urban bus $\mathrm{NO}_{\mathrm{x}}$ standard (5.0 grams/bhp-hr between now and 1995, and 4.0 grams/bhp-hr after 1995) and a lower $\mathrm{NO}_{x}$ standard at which a low-emission bus would be certified. Thus, emission standards, not estimated on-road emission rates, were used to calculate emission reductions. Emissions in grams/bhp-hr were converted to emissions in grams/mile using conversion factors of $4.3,4.3$, and $4.1 \mathrm{bhp}-\mathrm{hr} / \mathrm{mile}$ for diesel, methanol, and CNG buses, respectively. A lifetime of 12 years with 500,000 accumulated miles was assumed for methanol and CNG buses.

In its cost estimates, CARB included the costs of diesel, methanol, and natural gas, the costs of refueling stations for handling 200 buses or 10 buses, incremental prices of methanol and CNG buses, and operation costs for CNG compressors. The present value of lifetime costs was calculated for each bus type with an inflation rate of $3 \%$ and a currentterm discount rate of $10 \%$. Lifetime emissions, on the other hand, were calculated as the straight sum of emissions over the 500,000 miles, no discounting was applied to emissions occurring each year.

CARB's cost-effectiveness estimates are adjusted in Table 2 to include discounting to emissions. A real-term discount rate of $6 \%$ is assumed over the 12 -year lifetime of the buses, and uniform emission reductions are assumed for each of the 12 years.

Harrington and McConnell 1993

Harrington and McConnell, of Resources for the Future, completed a study in 1993 to estimate the cost-effectiveness of a remote sensing and an enhanced I/M program. To estimate emission reductions, they divided vehicles into five groups (normal, marginal, high, 
very high, and super emissions), and assigned vehicle distribution and emission factors to each group. Emission factors for each vehicle group were based on the United States Environmental Protection Agency's (EPA's) estimates, which might have been calculated using Mobile5a. Harrington and McConnell assumed that the remote sensing and the enhanced I/M program would identify vehicles in the very high and super emission groups and require emission tests and repairs to vehicles in these two groups.

Harrington and McConnell included in their remote sensing program cost estimates capital and operating costs for the remote sensing equipment; the costs of notifying and inspecting failing vehicles; and the cost of repairing failing vehicles. For the enhanced I/M program, they simply assumed a cost of $\$ 50$ per vehicle for a biennial $\mathrm{I} / \mathrm{M}$ program. The study took into account the fuel savings attributable to the remote sensing and the $\mathrm{I} / \mathrm{M}$ program.

In estimating emission reductions, Harrington and McConnell accounted for $\mathrm{HC}$ exhaust and evaporative emissions only, and ignored emissions of other pollutants. Their cost-effectiveness estimates are adjusted in Table 2 to include reductions in $\mathrm{CO}$ and $\mathrm{NO}_{\mathrm{x}}$ emissions as well as in $\mathrm{HC}$ emissions. We have assumed here that $\mathrm{NO}_{\mathrm{x}}$ reductions are $50 \%$ of $\mathrm{HC}$ reductions, and $\mathrm{CO}$ reductions are ten times as great as $\mathrm{HC}$ reductions. The sum of $\mathrm{HC}+\mathrm{CO} / 7+\mathrm{NO}_{x}$ is used in our cost-effectiveness calculation.

National Petroleum Council 1993

In 1993, the national Petroleum Council (NPC) conducted a comprehensive study to analyze the impacts of federal RFG requirements on the U.S. petroleum refining industry. In estimating RFG emission reductions, NPC estimated baseline emissions using Mobile4.1 for 1990 model-year vehicle technologies. Use of 1990 vehicle technologies may overestimate RFG emission reductions, because later vehicle technologies will certainly result in lower RFG emission reductions. Emissions only for the six summer months (April to September) were used in the study. Emission reductions for VOC and $\mathrm{NO}_{\mathrm{x}}$ were considered, while emission reductions for other pollutants were ignored. Only vehicular emissions were considered; VOC emissions during gasoline transportation, storage, and distribution were ignored. NPC believed that benzene reductions together with VOC reductions contribute to air toxic reductions. NPC study subtracted the portion of the RFG cost for benzene control from the total RFG cost to indirectly account for air toxic reductions.

NPC estimated RFG costs by including both refining costs and the RFG fuel economy penalty cost.

Compared with studies by CARB and Sierra, the NPC study shows significantly lower RFG control costs, probably because of NPC's use of 1990 vehicle technologies in its baseline emission estimation.

NPC's cost-effectiveness estimates are adjusted in Table 2 to include emission reductions of $\mathrm{CO}$ and $\mathrm{SO}_{\mathrm{x}}$ as well as $\mathrm{HC}$ and $\mathrm{NO}_{\mathrm{x}}$. Using Sierra's emission estimates, emissions reductions for $\mathrm{HC}+\mathrm{CO} / 7+\mathrm{NO}_{x}+\mathrm{SO}_{x}$ are estimated to be 2.41 times as much as those for $\mathrm{HC}+\mathrm{NO}_{\mathrm{x}}$.

Wang et al. 1993

Wang et al. estimated the cost-effectiveness of various alternative-fuel vehicles (AFVs) relative to conventional gasoline vehicles. Baseline gasoline vehicle emissions were estimated using Mobile5a. Because Mobile5a underestimates actual on-road emissions, they established a case under which Mobile5a-estimated emissions for $\mathrm{HC}$ and $\mathrm{CO}$ were increased by a factor of two to reflect actual on-road emissions.

Wang et al. estimated emission reductions of AFVs based on AFV emission testing 
results and on development of future AFV emission control technologies. To account for the uncertainties in future AFV emission reductions, they established two AFV emission reduction scenarios - low and high. Emissions of $\mathrm{HC}, \mathrm{CO}, \mathrm{NO}, \mathrm{PM}, \mathrm{SO}_{\mathbf{x}}$, and air toxics were included in the study. HC emissions from different AFV types were adjusted using their ozone reactivity factors. The present value of life-cycle vehicle emission reductions was calculated on the basis of a real-term discount rate of $6 \%$. Annual emissions were used in the cost-effectiveness calculation.

Cost estimates calculated by Wang et al. included vehicle incremental costs, fuel costs, changes in vehicle operation costs, and miscellaneous costs such as vehicle registration fees and $\mathbf{I} / \mathbf{M}$ fees. The present value of vehicle life-cycle costs was calculated on the basis of a real-term discount rate of $6 \%$. To account for uncertainties in vehicle incremental costs and fuel costs, Wang et al. established two cost scenarios - a low and a high cost scenario. AFV cost-effectiveness was calculated for each combination of emission reduction scenarios and cost scenarios.

Alberini et al. 1994

Alberini et al., of Resources for the Future, recently conducted a study to evaluate the cost-effectiveness of vehicle scrappage. In estimating emissions, they established an "emission supply function" in which the total emission reductions achieved by a scrappage program are a function of the offer prices for scrapped vehicles. They estimated remaining life, annual VMT, and total number of vehicles scrapped as functions of the offer prices. Emission reductions of vehicle scrappage were calculated as the emission difference between scrapped vehicles and replacement vehicles. Emission rates of scrapped vehicles were based on scrappage vehicle emission tests; emissions of replacement vehicles were estimated with Mobile5a. Alberini et al. assumed the same annual VMT for scrapped vehicles and replacement vehicles. Annual emissions were considered, except for evaporative HC emissions, for which emissions only in the summer six months were considered.

Alberini et al. assumed various offer prices, and calculated cost-effectiveness at each assumed offer price. In addition to the offer price, they assumed a cost of $\$ 100$ per vehicle for vehicle testing and disposal and program administration.

Alberini et al. calculated cost-effectiveness for $\mathrm{HC}$ reductions by assigning all costs to $\mathrm{HC}$ reductions, and ignored emission reductions of $\mathrm{NO}_{\mathrm{x}}$ and $\mathrm{CO}$. Their cost-effectiveness is adjusted in Table 2 to include reductions for $\mathrm{HC}+\mathrm{CO} / 7+\mathrm{NO}_{x}$. We have also applied a realterm emission discount rate of $6 \%$ to emission reductions over two years - the remaining lifetime of scrapped vehicles assumed by Alberini et al.

California Air Resources Board 1994

CARB has recently reviewed the technology feasibility, costs, and emission reductions of its adopted LEV program. By using EMFAC7F to estimate emission reductions of LEV types, CARB assumed that LEV types would reduce both zero-mile emission rates and emission deterioration rates. In calculating electric vehicle (EV) emission reductions, CARB considered power plant emissions, and also took into account vehicle exhaust and evaporative emissions and gasoline marketing emissions. It appears that CARB considered annual emissions in cost-effectiveness calculation, but did not apply emission discounting to lifetime emissions of LEV types.

In its cost estimates, CARB included hardware, assembly, shipping, warranty, support, legal and administrative, capital recovery, and dealer costs. CARB did not include vehicle operation cost differences caused by implementing LEV standards (such as fuel economy penalty, and maintenance of emission control systems). CARB stated that its estimates were 
based on the costs of implementing necessary emission control technologies in the long term, rather than during the initial transitional period, on which manufacturer-sponsored studies are often based. This may be the major reason why CARB's cost estimates are significantly lower than manufacturers' estimates.

CARB calculated cost-effectiveness using two methods. For the first, total cost is divided by $\mathrm{ROG}+\mathrm{CO} / 7+\mathrm{NO}_{\mathrm{x}}$. The second method involves allocating one-half of the total cost to emission reductions of $\mathrm{ROG}$ and $\mathrm{NO}_{\mathrm{x}}$, and the other half to reductions of toxic emissions; CO emissions were ignored. Results estimated using the first method are cited in Table 2. CARB's cost-effectiveness is adjusted in Table 2 to apply discounting to emission reductions. DRI/McGraw-Hill 1994

DRI/McGraw-Hill recently conducted a study to evaluate the economic consequences of CARB's LEV program in California. Using EMFAC7F, DRI calculated baseline emissions on the basis of federal RFG requirements and federal Tier 2 standards. Use of federal Tier 2 standards for California, which may not be appropriate, certainly underestimates LEV emission reductions. It is not clear what emission reductions were assumed in EMFAC7F and how the model generated emission reductions by the LEV program and by AFVs. DRI took into account $\mathrm{HC}$ and $\mathrm{NO}_{x}$ emissions, but ignored emissions of other pollutants.

DRI assumed that the introduction of high-pried LEVs and AFVs would suppress new vehicle sales, and consequently, old vehicles would be driven longer, causing increased emissions. Because of this emission offsetting effect by old vehicles, DRI (in some cases) estimated unrealistic net zero emission changes by LEVs and AFVs.

In its cost estimates, DRI included costs associated with capital investment, employment impacts, and other effects as well as direct costs such as vehicle hardware, infrastructure, and fuel costs. For example, DRI stated that cross-subsidy between AFVs and conventional vehicles would result in a net cost increase of $\$ 900$ million to $\$ 8.4$ billion in 2010 , which translated into a price increase of $\$ 400$ to $\$ 4,400$ for each conventional vehicle. DRI also estimated the cost burden on California's economy incurred by those who did not buy new cars, or who reduced their use of natural gas and electricity because of higher prices caused by AFV and EV subsidies. DRI estimated that the cost burden would range from $\$ 20$ to $\$ 900$ million annually.

One cost items included in the DRI studies is transfer costs, which should not be included in a social cost-effectiveness calculation. DRI's inclusion of transfer costs and indirect economic costs in its estimates resulted in extremely high control costs.

It is not clear whether DRI used seasonal or annual emissions in its cost-effectiveness calculation, or whether DRI applied emission discounting in calculating lifetime emission reductions. Thus, adjustments to reflect seasonal emissions and emission discounting cannot be made here. However, we have adjusted DRI's estimates to include CO emission reductions. Lareau 1994

Lareau, of American Petroleum Institute, recently conducted a comprehensive study to review the methodologies used to calculate cost-effectiveness. He explored such important issues as emission discounting, allocation of costs among different pollutants, and estimation of baseline emissions. Lareau emphasized that the baseline emission calculation should take into account the programs already implemented or required by law. He further proposed that, when the order of implementing proposed programs is important in determining a program's cost-effectiveness, all order combinations should be simulated to determine which ordering and which program will provide the lowest cost.

Lareau estimated the cost-effectiveness of CARB's LEV program, an enhanced I/M 
program, an old car scrappage program, and RFG requirements. In estimating emission reductions of the enhanced I/M program, Lareau used Mobile5a default values designed for the enhanced I/M program. Emission reductions of the old car scrappage program were calculated as the emission difference between scrapped cars and replacement cars. Emissions of both scrapped and replacement cars were calculated using Mobile5a. Lareau assumed that the scrappage program would target vehicles at least 12 years old. He assumed a remaining lifetime of 3 years for scrapped vehicles.

Lareau also used Mobile5a to estimate the emission rates of LEV types. By using Mobile5a, he implicitly assumed that LEV types would reduce zero-mile emissions, but not emission deterioration rates. In contrast, CARB assumes (in its EMFAC) that LEVs reduce both zero-mile emissions and emission deterioration rates. Thus, LEV emission reductions estimated by Lareau are smaller than those estimated by CARB.

Lareau estimated emission reductions of RFG based on fleet average emissions calculated using Mobile5a. To calculate lifetime emissions of LEV types, he assumed a lifetime of 15 years, and applied a real-term emission discount rate of $5 \%$.

Lareau estimated the cost of a biennial centralized enhanced I/M program by including inspection cost, average repair cost, fuel savings, and motorist time spent. He assumed offer prices of $\$ 600$ to $\$ 900$ for vehicle scrappage. On the basis of various studies on LEV costs, Lareau assumed these costs - \$25-\$70 per TLEV, \$170-\$310 per LEV, and \$415-\$645 per ULEV, all relative to a Tier 1 car. Lareau adopted the following costs for RFG based on previous studies - \$0.05-\$0.09 per gallon for federal Phase $1 \mathrm{RFG}, \$ 0.09-\$ 0.12$ for federal Phase 2 RFG, and \$0.15-\$0.26 for California Phase 2 RFG, all relative to conventional gasoline.

Lareau calculated cost-effectiveness for VOC control. By allocating a portion of a measure's total cost to VOC control based on $\mathrm{CO}$ attainment status and the role of $\mathrm{NO}_{\mathrm{x}}$ emissions in ozone formation. Specifically, he suggested four ways of allocating costs among pollutants under four different cases. First, if a region is ozone nonattainment but CO attainment, and if increases in $\mathrm{NO}_{\mathrm{x}}$ do not significantly affect ozone levels, all costs were allocated to VOC control. Second, if a region is both ozone and CO nonattainment, and if increases in $\mathrm{NO}_{\mathrm{x}}$ emissions do not significantly increase ozone levels, costs were divided between VOC and $\mathrm{CO}$. CO opportunity costs were estimated using $\mathrm{CO}$ tonnage reductions and a cost of $\$ 200$ per ton of CO. The estimated CO opportunity costs were then subtracted from the total costs, and the remaining costs were assigned to VOC control. Third, if a region is ozone nonattainment but $\mathrm{CO}$ attainment, and if $\mathrm{NO}_{\mathrm{x}}$ has a significant effect on ozone formation, the marginal contribution of $\mathrm{NO}_{x}$ to ozone formation was assumed to be about onehalf that of VOC. Costs allocated to VOC control were calculated as (total costs $\mathrm{x}$ [1-1/2 $\mathrm{x}$ $\left.\mathrm{NO}_{\mathrm{x}} /\left(\mathrm{VOC}+\mathrm{NO}_{\mathrm{x}}\right)\right]$ ). Finally, if a region is both ozone and $\mathrm{CO}$ nonattainment, and if $\mathrm{NO}_{\mathrm{x}}$ affects ozone formation, Lareau applied a combination of the allocations used in the second and third cases. For RFG, he allocated 15\% of RFG costs to air toxic emission reductions.

Within a control program, a variety of alternatives may be available. Lareau pointed out that, while average cost-effectiveness can be calculated for the program, marginal costeffectiveness can be calculated for each of the alternatives within the program. He maintained that in order to provide guidance on which alternatives should be included in the program, marginal cost-effectiveness, as well as average cost-effectiveness, must be calculated.

Lareau maintained that emission reductions in only the nonattainment season should be included in cost-effectiveness calculation. He assumed a nonattainment season of six 
months a year.

In general, Lareau estimated higher control costs than other researchers for the following reasons. First, he used Mobile5a to estimate emission reductions of LEV type; Mobile5a probably underestimates LEV emission reductions. Second, when considering CO emission reductions, Lareau used an opportunity of $\$ 200$ per ton of $C O$ emissions, while other studies added $\mathrm{CO} / 7$ to total emission reductions. Lareau's approach results in less $\mathrm{CO}$ impact on cost-effectiveness than the other approach. Third, Lareau calculated marginal costeffectiveness for individual LEV types, which is higher than the average cost-effectiveness calculated in other studies. Finally, Lareau assumed stringent control measures in calculating baseline emissions, which decreases the emission reductions of the evaluated programs.

\section{Sierra Research, Inc. 1994}

Sierra recently conducted a study for American Automobile Manufacturers Association to evaluate the cost-effectiveness of CARB's LEV program. In calculating LEV emission reductions, Sierra included emissions in only the nonattainment season and nonattainment areas; emissions occurring in attainment seasons and in attainment areas were excluded. In California, Sierra accounted for annual emission reductions of ozone precursors. In the rest of the nation, Sierra accounted for one third of the annual emission reductions. Sierra accounted for one third of annual $\mathrm{CO}$ emission reductions in all states. By using Mobile5a to estimate LEV emission reductions, Sierra implicitly assumed that the LEV program would reduce zero-mile emissions, but not emission deterioration rates.

Sierra calculated the present value of vehicle lifetime emission reductions using a realterm discount rate of 5\%, and calculated the cost-effectiveness of LEV types in California and nationwide. Sierra accounted for emission reductions of $\mathrm{HC}$ and $\mathrm{NO}_{\mathrm{x}}$ and $\mathrm{CO}$ by using the sum of $\mathrm{HC}+\mathrm{CO} / 7+\mathrm{NO}_{x}$ in the cost-effectiveness calculation. Emissions of other pollutants were not considered.

In estimating the amount of emissions reduced by zero-emission vehicles (ZEVs), Sierra decreased estimated ZEV emission reductions by multiplying them by a factor 0.788 , because Sierra believed that EVs would travel only $78.8 \%$ of the annual VMT made by gasoline vehicles, and assumed that the shortfall in the annual VMT by EVs would be made up by gasoline vehicles.

Based on cost data provided by vehicle manufacturers and vendors of emission control equipment, Sierra assumed costs for individual LEV types, relative to the cost of a 1993 federal car. Sierra's assumed costs were generally higher than those used in other studies. It is not clear whether and how fuel costs and other operating costs of CNG LEV/ULEV and of ZEVs were taken into account.

Sierra estimated high cost-effectiveness for LEV types, especially for ZEVs, mainly because Sierra assumed very high costs for LEVs, and because its use of Mobile5a tended to result in small emission reductions.

Sierra calculated cost-effectiveness of LEVs for the entire U.S. by assuming that half of the nation is in attainment, thus accounting for half of the emission reductions by LEVs. Because there is no proposal to adopt California's LEV program on a national scale, Sierra's nationwide cost-effectiveness estimates have little value. Sierra's assumption that ZEVs travel $78.8 \%$ of the annual VMT by gasoline vehicles is less convincing. Thus, Sierra's adjustment of ZEV emission reductions based on this assumption is factored out in Table 2. Summary of Past Studies and Their Results

Table 1 presents a summary of the methodological assumptions used in each of the 
studies discussed above. While annual emissions were used in the majority of the studies, seasonal emissions were used in a few. The results based on seasonal emissions are adjusted in Table 2 for comparison to those based on annual emissions. To determine seasonal emission-based cost-effectiveness, simply divide the annual emission-based results by the ratio of seasonal emissions to annual emissions.

All studies used either EPA's Mobile or CARB's EMFAC model to estimate baseline emissions and emission reductions of control measures. Recent studies have revealed out that Mobile and EMFAC may significantly underestimate actual on-road emissions;specifically, emissions of $\mathrm{HC}$ and $\mathrm{CO}$ may be underestimated as much as by $200 \%$. This underestimation of on-road emissions by Mobile and EMFAC certainly results in underestimation of emission reductions of control measures, which leads to overestimation of control costs. In their study, Wang et al. (1993) adjusted Mobile5a-estimated emissions to actual on-road emissions, and they found that use of adjusted on-road emissions can significantly reduce AFV cost-effectiveness.

Some of the reviewed studies did not apply emission discounting in calculating lifetime vehicle emissions. For these studies, adjustments are made here to apply discounting to emissions. Note that emission discounting is not applicable for measures that affect annual mobile source emissions rather than vehicle lifetime emissions. Such measures include RFG requirements, I/M programs, and remote sensing.

Many studies ignored emissions reductions for $\mathrm{CO}, \mathrm{SO}_{\mathrm{x}}, \mathrm{PM}$, and air toxics. To the extent possible, adjustments are made here to include emission reductions of these pollutants. As Table 1 shows, even after the adjustments, emission reductions of $\mathrm{SO}_{x}, \mathbf{P M}$, and air toxics are still not included in some studies, which may well contribute to the differences in costeffectiveness among the studies.

While some studies explicitly excluded emissions in attainment areas, others implicitly assumed that the evaluated measures would be adopted in nonattainment areas. Thus, virtually all of the reviewed studies estimated cost-effectiveness for nonattainment areas.

Table 2 presents original and adjusted cost-effectiveness estimates for various measures from the reviewed studies. As the table shows, the adjustments made here generally cause decreases in control costs, except for the three studies by CARB, where adjustments lead to moderate cost increases. Dramatic reductions in control costs from the adjustments occur for the studies by Sierra (1991 and 1994), Harrington and McConnell (1993), NPC (1993), and DRI/McGraw-Hill (1994). These dramatic reductions are caused by (1) the change from seasonal emissions used in original estimates to annual emissions, (2) inclusion of emission reductions of certain given pollutants otherwise ignored in the original estimates, or (3) a combination of both. No methodological adjustments were made for the study by Lareau (1994) and the study by Wang et al. (1993).

The cost-effectiveness of various mobile source control measures can now be compared according to the adjusted cost-effectiveness estimate for each control measure. Figure 1 presents a comparison of the cost-effectiveness among various control measures. The figure presents minimum, average, and maximum cost-effectiveness for each measure calculated from the adjusted results in the reviewed studies. The range for a measure shows the uncertainty in the measure's cost-effectiveness. Cost-effectiveness for some measures was estimated in only one study. Consequently, no average and maximum cost-effectiveness is available for these measures. The lack of average and maximum cost-effectiveness for some measures does not indicate that less uncertainty is associated with the cost-effectiveness values for these measures. 
Table 1. Summary of Methodological Assumptions Used in Past Studies

\begin{tabular}{|c|c|c|c|c|c|}
\hline \multirow{2}{*}{ Study } & \multirow{2}{*}{ Emissions } & \multirow{2}{*}{ Emission model } & \multirow{2}{*}{$\begin{array}{l}\text { Emission } \\
\text { discounting }\end{array}$} & \multicolumn{2}{|c|}{ Pollutants ignored } \\
\hline & & & & Before adjustments & After adjustments \\
\hline CAR 1991 & Annual & EMFAC7EP & Not applicable & PM & PM \\
\hline Sierra 1991 & Annual & EMFAC7EP & Not applicable & $\mathrm{CO}, \mathrm{SO}_{x}, \mathrm{PM}$, air toxics & PM \\
\hline CARB 1993: scrappage & Annual & EMFAC7F & No & $\mathrm{CO}, \mathrm{SO}_{\mathrm{x}}, \mathrm{PM}$, air toxics & $\mathrm{SO}_{x}, \mathrm{PM}$, air toxics \\
\hline CARB 1993: clean buses & Annual & Standards & No & $\begin{array}{l}\mathrm{HC}, \mathrm{CO}, \mathrm{SO}_{x}, \mathrm{PM}, \text { air } \\
\text { toxics }\end{array}$ & $\begin{array}{l}\mathrm{HC}, \mathrm{CO}, \mathrm{SO}_{x}, \mathrm{PM}, \\
\text { air toxics }\end{array}$ \\
\hline Harrington et al. 1993 & Annual & Mobile5a(?") & No applicable & $\begin{array}{l}\mathrm{NO}_{x}, \mathrm{CO}, \mathrm{SO}_{y}, \mathrm{PM} \text {, air } \\
\text { toxics }\end{array}$ & $\mathrm{SO}_{x}, \mathrm{PM}$, air toxics \\
\hline NPC 1993 & Seasonal & Mobile4.1 & Not applicable & $\mathrm{CO}, \mathrm{SO}_{\mathbf{x}}, \mathrm{PM}$ & PM \\
\hline Wang et al. 1993 & Annual & Mobile5a\&on-road adj. & Yes & None & None \\
\hline Alberini et al. 1994 & Annual & Mobile5a & No & $\begin{array}{l}\mathrm{NO}_{x}, \mathrm{CO}, \mathrm{SO}_{x}, \mathrm{PM}, \text { air } \\
\text { toxics }\end{array}$ & $\mathrm{SO}_{x}, \mathrm{PM}$, air toxics \\
\hline CARB 1994 & Annual & EMFAC7F & No & $\mathrm{SO}_{x}, \mathrm{PM}$, air toxics & $\mathrm{SO}_{\mathrm{x}}, \mathrm{PM}$, air toxics \\
\hline DRI/McGraw-Hill 1994 & $?^{a}$ & EMFAC7F & $?^{2}$ & $\mathrm{CO}, \mathrm{SO}_{x}, \mathrm{PM}$, air toxics & $\mathrm{SO}_{x}, \mathrm{PM}$, air toxics \\
\hline Lareau 1994 & Annual \& seasonal & Mobile5a & Yes & $\mathrm{SO}_{x}, \mathrm{PM}$, air toxics & $\mathrm{SO}_{x}, \mathrm{PM}$, air toxics \\
\hline Sierra 1994 & Seasonal & Mobile5a & Yes & $\mathrm{SO}_{\mathrm{x}}, \mathrm{PM}$, air toxics & $\mathrm{SO}_{x}, \mathrm{PM}$, air toxics \\
\hline
\end{tabular}

- For RFG requirements, Lareau allocated $15 \%$ of the RFG cost to air toxic reductions. Thus, air toxic reductions were indirectly considered in RFG cost-effectiveness. 
Table 2. Cost-Effectiveness of Mobile Source Control Measures: Original and Adjusted Estimates

\begin{tabular}{|c|c|c|c|}
\hline Measure & Study & Original \$/ton & Adjusted $\$ /$ ton $^{b}$ \\
\hline \multirow[t]{3}{*}{$\mathbf{I} / \mathbf{M}$} & Sierra 1994 & 1,166 & 451 \\
\hline & Harrington et al. 1993 & 4,984 & 1,702 \\
\hline & Lareau 1994 & 6,600 & 6,600 \\
\hline Remote sensing & Harrington et al. 1993 & 3,688 & 1,259 \\
\hline Enh. evap. control & Sierra 1994 & 4338 & 1,297 \\
\hline \multirow[t]{3}{*}{ LEV } & CARB 1994 & 1,180 & 1,688 \\
\hline & Sierra 1994 & 14,146 & 8,804 \\
\hline & Lareau 1994 & 60,875 & 60,875 \\
\hline RVP reduction & Sierra 1994 & 1,527 & 1,527 \\
\hline \multirow[t]{3}{*}{ TLEV } & CARB 1994 & 1,360 & 1,946 \\
\hline & Sierra 1994 & 9,767 & 5,327 \\
\hline & Lareau 1994 & 14,233 & 14,233 \\
\hline \multirow[t]{4}{*}{ Fed. Phase 2 RFG } & NPC 1993 & 10,500 & 2,289 \\
\hline & Sierra 1994 & 4,555 & 4,555 \\
\hline & Lareau 1994 & 12,250 & 12,250 \\
\hline & Sierra 1991 & 50,500 & 17,726 \\
\hline \multirow[t]{3}{*}{ ULEV } & CARB 1994 & 1,700 & 2,432 \\
\hline & Sierra 1994 & 18,842 & 10,274 \\
\hline & Lareau 1994 & 194,075 & 194,075 \\
\hline \multirow[t]{3}{*}{ CNG vehicles } & Wang et al. 1993 & 2,575 & 2,575 \\
\hline & CARB 1993 & 4,150 & 5,946 \\
\hline & Sierra 1994 & 24,415 & 13,313 \\
\hline \multirow[t]{4}{*}{ Calif. Phase 2 RFG } & NPC 1993 & 13,000 & 2,834 \\
\hline & Sierra 1994 & 7,451 & 7,451 \\
\hline & CARB 1991 & 12,600 & 16,157 \\
\hline & Sierra 1991 & 59,200 & 20,779 \\
\hline \multirow[t]{4}{*}{ Vehicle scrappage } & CARB 1993 & 4,400 & 3,170 \\
\hline & Alberini et al. 1994 & 6,573 & 4,141 \\
\hline & Sierra 1994 & 7,380 & 7,380 \\
\hline & Lareau 1994 & 14,013 & 14,013 \\
\hline Tier 1 standards & Sierra 1994 & 12,145 & 4,048 \\
\hline
\end{tabular}




\begin{tabular}{|c|c|c|c|}
\hline \multirow[t]{2}{*}{ Methanol vehicles } & Wang et al. 1993 & 9,298 & 9,298 \\
\hline & CARB 1993 & 9,150 & 13,109 \\
\hline OBD II & Sierra 1994 & 17,912 & 9,767 \\
\hline Tier 2 standards & Sierra 1994 & 42,988 & 14,329 \\
\hline \multirow[t]{4}{*}{ ZEV } & Wang et al. 1993 & 14,738 & 14,738 \\
\hline & CARB 1994 & 12,100 & 17,310 \\
\hline & Sierra 1994 & 102,093 & 43,866 \\
\hline & DRI/McGraw-Hill 1994 & 238,700 & 139,224 \\
\hline LPG vehicles & Wang et al. 1993 & 15,329 & 15,329 \\
\hline \multirow[t]{2}{*}{ LEV program } & DRI/McGraw-Hill 1994 & 27,200 & 15,865 \\
\hline & Lareau 1994 & 28,541 & 28,541 \\
\hline $\begin{array}{l}\text { Ethanol vehicles } \\
\text { Three undenined terms } \\
\text { neration on-board diagn } \\
\text { Original estimates have } \\
\text { ductions The adiusted }\end{array}$ & $\begin{array}{l}\text { Wang et al. } 1993 \\
\text { table are derined here. KVF } \\
\text { ystem; and LPG represents liq }\end{array}$ & $\begin{array}{l}\frac{27,923}{\text { or pressure }} \\
\text { ounting, an }\end{array}$ & $\begin{array}{l}\frac{27,923}{\text { nts the nex }} \\
\text { ant emissior }\end{array}$ \\
\hline
\end{tabular}

In determining minimum, average, and maximum cost-effectiveness values for each measure, the cost-effectiveness for the LEV type, the ULEV type, and the LEV program estimated by Lareau and the cost-effectiveness for the LEV program and the ZEV estimated by DRI/McGraw-Hill were excluded. we excluded these estimates because Lareau calculated marginal control costs for these LEV types, while other studies estimated average control costs for the same LEV types, and because DRI/McGraw-Hill included transfer costs and indirect economic costs, which other studies generally did not include. In addition, because of the difficulty in identifying certain methodological assumptions used by DRI/McGraw-Hill, adequate methodological adjustments could not be made for the study. Thus, the comparison of the DRI study the other studies reviewed may not be appropriate.

Although precise, quantitative conclusions cannot be drawn from Figure 1, the figure does help us to draw some general conclusions about the relative cost-effectiveness of various control measures. In general, the enhanced $\mathrm{I} / \mathrm{M}$ program, remote sensing, enhanced vehicle evaporative emission control, and Reid vapor pressure (RVP) reductions are cost-effective. The cost-effectiveness of TLEV, LEV, ULEV, federal Phase 2 RFG, California Phase 2 RFG, CNG vehicles, and old car scrappage is subject to great uncertainty, although these measures look relatively cost-effective. Methanol vehicles, the next generation on-board diagnosis system (OBD II), Tier 2 standards, ZEV, liquified petroleum gas vehicles, and ethanol vehicles are generally expensive. The greatest uncertainty exists in ZEV cost-effectiveness, mainly because of very different cost assumptions used in the ZEV studies.

Despite our efforts to make the reviewed studies comparable to the extent possible, the adjusted estimates are by no means completely comparable. Inconsistency exist among the studies regarding pollutants included in calculating cost-effectiveness even after our adjustments. For example, as Table 1 shows, after adjustments, emissions of $\mathrm{PM}, \mathrm{SO}_{\mathrm{z}}$, and air toxics are still not included in some of the reviewed studies even after adjustments. Nonetheless, this study reveals a general trend of the cost-effectiveness of mobile source control measures as shown in Figure 1. 


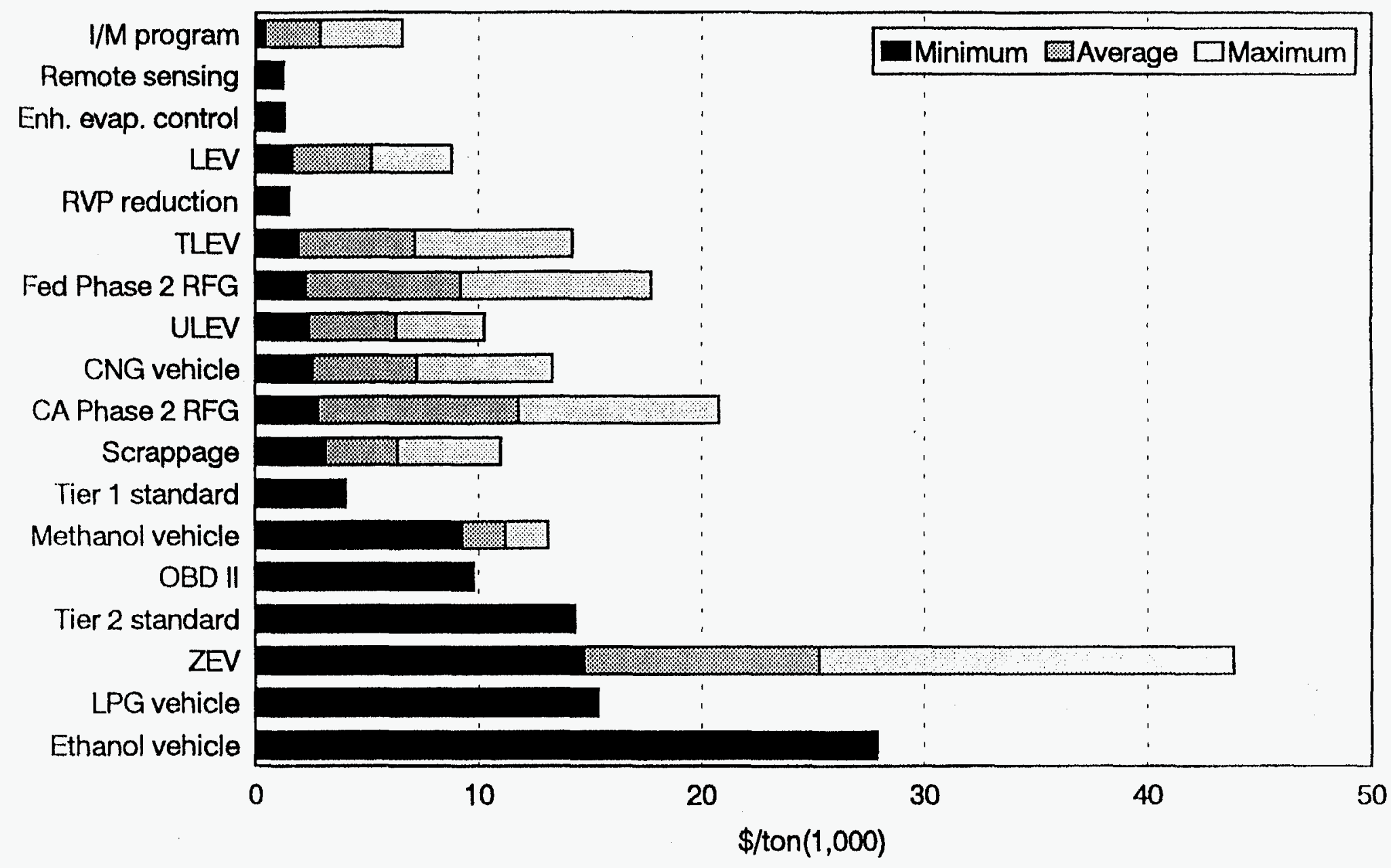

Figure 1. Cost-Effectiveness of Mobile Source Control Measures (based on adjusted cost-effectiveness, 1993 dollars) 
Although cost-effectiveness values reveal how expensive it is to reduce one ton of emissions using a given measure, they do not indicate the magnitude of emission reductions achievable at the estimated cost. For example, although vehicle scrappage may be costeffective, the amount of emissions reduced from vehicle scrappage may be limited, especially in the future when vehicles will likely experience less severe emission system deterioration over their lifetimes. In some regions, control measures with higher control costs may have to be adopted in order to meet emission and air quality requirements. Thus, in determining what control measures are to be implemented, both cost-effectiveness and the magnitude of emission reductions achieved by the control measures must be considered.

Conclusions

Calculation of emission control cost-effectiveness involves methodological as well as technical assumptions. While technical assumptions are related to values assumed for costs and emission reductions, methodological assumptions are related to such issues as what costs are accounted for, how emission reductions are calculated, and what pollutants are included. To adequately and correctly estimate comparable cost-effectiveness, we proposed that the following methodological assumptions be consistently applied to mobile source costeffectiveness calculation. For cost estimation, social as well as private costs need to be considered, and costs should be estimated at the consumer, rather than the manufacture, level. For emission reduction estimation, baseline emissions should be calculated by taking into account the control programs already implemented. While emissions in nonattainment seasons and nonattainment areas are directly related to attainment of air quality standards, emissions in attainment seasons and attainment areas should not be treated as having zero value. For control measures with multiple-pollutant emission reductions, emission reductions of all affected pollutants should be taken into account. To be consistent with cost estimates where discounting is applied, discounting should be applied to emissions as well.

The 11 studies of mobile source control cost-effectiveness reviewed here show wide ranges in cost-effectiveness, and because of different methodological assumptions used in these studies, their cost-effectiveness estimates are not comparable. Necessary methodological adjustments to the original estimates were made to allow comparison of the study results. The adjustments applied in this paper include consideration of emission reductions of all affected pollutants (to the extent allowed by emission data), application of emission discounting, and use of annual emissions in cost-effectiveness calculation.

Although precise, quantitative conclusions regarding mobile source control costeffectiveness cannot be drawn from the adjusted cost-effectiveness results, the results do show some general trends of the relative cost-effectiveness of various mobile source control measures.

\section{Acknowledgement}

This work is sponsored by the U.S. Department of Energy, Assistant Secretary for Energy Efficiency and Renewable Energy, Office of Alternative Fuels, under contract W-31109-ENG-38. However, the author is solely responsible for the views and opinions expressed and the results presented in this paper.

\section{References}

Alberini, A., D. Edelstein, W. Harrington, and V. McConnell, 1994, Reducing Emissions from Old Cars: the Economics of the Delaware Vehicle Retirement Program, Resources for the Future discussion paper 94-27, Resources for the Future, Washington, D.C., April.

California Air Resources Board, 1991, Proposed Regulations for California Phase 2 Reformulated Gasoline, Technical Support Document, Sacramento, Calif., Oct. 4. 
California Air Resources Board, 1993, Mobile Source Emission Reduction Credits, Guidelines for the Generation and Use of Mobile Source Emission Reduction Credits, California Air Resources Board, Stationary Source Division and Mobile Source Division, Sacramento, Calif., Feb. 19.

California Air Resources Board, 1994, Staff Report: 1994 Low-Emission Vehicle and ZeroEmission Vehicle Program Review, California Air Resources Board, Mobile Source Division, El Monte, Calif., April.

DRI/McGraw-Hill, 1994, Economic Consequences of Adopting California Programs for Alternative Fuels and Vehicles, Washington, D.C., Feb. 22.

Harrington, W. and V. D. McConnell, 1993, Cost-Effectiveness of Remote Sensing of Vehicle Emissions, Resources for the Future discussion paper QE93-24, Resources for the Future, Washington, D.C., Sept.

Lareau, T. J., 1994, Improving Cost-Effectiveness Estimation: a Reassessment of Control Options to Reduce Ozone Precursor Emissions, American Petroleum Institute, Washington, D.C., Aug.

National Petroleum Council, 1993, U.S. Petroleum Refining: Meeting Requirements for Cleaner Fuels and Refineries, Volume V-Refining Capability Appendix, National Petroleum Council, Washington, D.C., Aug.

Sierra Research, Inc., 1991, Cost-Effectiveness Analysis of CARB's Proposed Phase 2 Gasoline Regulations, prepared for Western States Petroleum Association, Sacramento, Calif., Nov. 18.

Sierra Research, Inc., 1994, The Cost-Effectiveness of Further Regulating Mobile Source Emissions, prepared for American Automobile Manufactures Association. Sacramento, Calif., Feb. 28.

Wang, Q., D. Sperling, and J. Olmstead, 1993, Emission Control Cost-Effectiveness of Alternative-Fuel Vehicles, Society of Automotive Engineers technical paper 931841, Society of Automotive Engineers, Warrendale, Penn. 